\title{
Electro-thermal Analysis of Power Converter Components in Low-Voltage DC Microgrids for Optimal Protection System Design
}

\author{
Michal Sztykiel, Steven Fletcher, Patrick Norman, Stuart Galloway and Graeme Burt
}

\begin{abstract}
Bidirectional power converters are considered to be key elements in interfacing the low voltage dc microgrid with an ac grid. However to date there has been no clear procedure to determine the maximum permissible fault isolation periods of the power converter components against the dc faults. To tackle this problem, this paper presents an electro-thermal analysis of the main elements of a converter: ac inductors, dc capacitors and semiconductors. In doing this, the paper provides a methodology for quantifying fault protection requirements for power converter components in future dc microgrids. The analysis is performed through simulations during normal and fault conditions of a low voltage dc microgrid. The paper develops dynamic electrothermal models of components based on the design and detailed specification from manufacturer datasheets. The simulations show the impact of different protection system operating speeds on the required converter rating for the studied conditions. This is then translated into actual cost of converter equipment. In this manner, the results can be used to determine the required fault protection operating requirements, coordinated with cost penalties for uprating the converter components.
\end{abstract}

Index Terms-- Microgrid, DC fault current, AC-DC power conversion, thermal design, power semiconductor diode switches, thermal stress, fault protection requirements.

\section{NOMENCLATURE}

$C_{\text {cap }} \quad$ nominal capacitance of dc capacitor

$c_{\text {core }} \quad$ core specific heat

$C_{L} \quad$ cable shunt capacitance

$c_{s} \quad$ specific heat of the heatsink

$C_{t h} \quad$ thermal capacitance

$C_{\text {th(core })}$ thermal capacitance, windings to ambient

$C_{t h(j-c)} \quad$ thermal capacitance, junction to case

$C_{t h(s-a)} \quad$ thermal capacitance, heatsink to ambient

$C_{\text {th(winding) }}$ thermal capacitance, core to ambient

$c_{\text {winding }} \quad$ windings specific heat

$f_{s w} \quad$ switching frequency

$i_{\text {latch }} \quad$ current level at which latch-up may occur

$I_{N} \quad$ nominal current (RMS)

$I_{\text {limit }} \%$ current limiting level made by a fault current limiter

$L_{\text {busbar }} \quad$ stray inductance of dc busbar

$L_{c a p} \quad$ equivalent series inductance of dc capacitor

This work has been carried out as part of the Rolls-Royce UTC Program. M. Sztykiel, P. Norman, S. Galloway and G. Burt are with the Department of Electronic, Electrical Engineering, University of Strathclyde, Glasgow G1 1RD,UK(email:michal.sztykiel@strath.ac.uk; steven.fletcher117@gmail.com; patrick.norman@strath.ac.uk; stuart.galloway@strath.ac.uk; graeme.burt@strath.ac.uk).

$\begin{array}{ll}L_{L} & \text { cable series inductance } \\ L_{s w} & \text { stray inductance of a semiconductor } \\ m_{s} & \text { mass of the heatsink } \\ P_{A C} & \text { nominal active power } \\ P_{d} & \text { instantaneous power losses } \\ P_{d, N} & \text { nominal power losses } \\ R_{b a t t e r y} & \text { parasitic resistance of a battery } \\ R_{\text {cap }} & \text { equivalent series resistance of dc capacitor } \\ R_{L} & \text { cable series resistance } \\ R_{l o a d} & \text { load resistance } \\ R_{s w} & \text { on-state resistance of a semiconductor } \\ R_{t h} & \text { thermal resistance } \\ R_{t h(c-s)} & \text { thermal resistance, case to heatsink } \\ R_{t h(j-c)} & \text { thermal resistance, junction to case } \\ R_{t h(s-a)} & \text { thermal resistance, heatsink to ambient } \\ T_{a m b} & \text { ambient temperature } \\ t_{b r e a k} & \text { fault breaking time } \\ T_{C, N} & \text { nominal (working) case temperature } \\ T_{h s, \text { max }} & \text { maximum allowed hot-spot temperature } \\ T_{h s, N} & \text { nominal (working) hot-spot temperature } \\ T_{j} & \text { junction temperature } \\ T_{j, m a x} & \text { maximum allowed junction temperature } \\ T_{j, N} & \text { nominal (working) junction temperature } \\ V_{c o r e} & \text { volume of core } \\ V_{t o t a l} & \text { total volume of ac inductor } \\ V_{\text {winding }} & \text { volume of windings } \\ Z_{t h(j-c)} & \text { transient thermal impedance, junction to case } \\ \delta_{c o r e} & \text { core density } \\ \delta_{\text {winding }} & \text { windings density } \\ \tau_{R C} & \text { thermal time constant } \\ & \end{array}$

\section{INTRODUCTION}

A micro-grid refers to the integration of distributed generation into an isolated and fully functional power system [1]. Micro-grids are designed to flexibly provide a continuous power supply within its range, independent to the interconnected remote supplies. As a result, micro-grid systems are especially attractive to emergency (hospitals, data centers) and mobile end-users (aircraft, traction, vehicles).

The selection of an optimal low voltage micro-grid architecture is based on the types of distributed resources, network and communication systems [2]. Power electronics converters play a key role here, as they interconnect sources with a network to provide an interface for a synchronized and controlled power supply to end-users.

In order to minimize cost, losses and volume, it has been 
proposed that future low voltage micro-grid architectures with a variety of distributed resources will be based on the dc distributed networks [3]. Compared to ac networks, dc microgrids may provide a simpler and more efficient interface between sources and loads by reducing the number of consecutive power conversion stages and consequently the number of required power converter units [4].

Electrical network protection is an important aspect related to the economic development of future dc architectures. The selection of commercially available protection devices needs to be well coordinated with the selection of the peak rating of network components. In this manner, an optimal compromise can be achieved between reliable fault protection and minimum cost.

On the contrary to ac networks, the appearance of short circuit faults in dc microgrids results in rapid rise of excessive fault current [5]. This has a significant impact on the dc system performance and protection methods of the power electronics converters. According to [1], it is possible to isolate the dc fault with the usage of commercial protection devices, such as fuses and circuit breakers to protect batteries and loads. However, the relative sensitivity of power converters can impose strict protection requirements, as this paper will highlight, hence limiting the use of conventional circuit breaking technologies [6-7].

IEC 61660-1 standard [9] defines methods and empirical formulas for estimating the dc short circuit currents. This provides a generally applicable method of calculation, which produces results of sufficient accuracy on the conservative side for the given application. This allows the calculation of fault current contributions coming from each individual source i.e. lead-acid battery, dc capacitor, etc. Based on the determined dc fault current levels, the IEC describes the procedure to estimate mechanical and thermal effects on rigid conductors e.g. cables and bus bars, which can be used in identifying protection system requirements.

However, the dc microgrids consist not only of the rigid conductors as shown in Fig. 1, but also of power electronics converters built from their own internal components: filters and semiconductors. As a consequence, identification of the protection system requirements should also include the impact made by the excessive fault current on converter components. Calculations of fault current using the IEC 61660-1 standard can also lead to some inaccuracies where active converters are included in the network [10].

The empirical formulas used to calculate dc short circuit currents flowing through the converter individual components have already been formulated in Laplace domain and described in [11]. However the use of formulas to accurately represent fault current is still challenging in closely coupled, parallel branch networks as analytic expressions can become large and complex [12]. Therefore network simulation remains a key part of the system analysis [13].

Beyond fault current calculation, the natural next step is to develop a technique, which can be used to estimate thermal effects on the converter elements and propose a design rationale for its fault protection system.

This paper presents such a method, which identifies the protection system operating requirements by estimating the relationship between the required fault clearing time and the converter components' ratings.

This paper also describes the development of new transient electro-thermal models of electrical components, which have not been covered in [9] along with the procedure to estimate the thermal effects of faults. As a result, the electro-thermal models of the components presented in this paper can be considered and challenged as a supplement to the models of the rigid components and used to determine the actual thermal effects on power converters during faults.

The fault analysis is based on the estimated transient temperature rise for the given ratings of the power converter components, which are subjected to the thermal stress during dc short-circuit faults. The obtained temperature variations are used to identify the required converter protection system operating times over a range of working temperatures.

Finally, the cost of the components is estimated for the range of working temperatures and operating times of the protection system so that dc fault protection requirements can be directly associated with an actual cost of the power converter components.

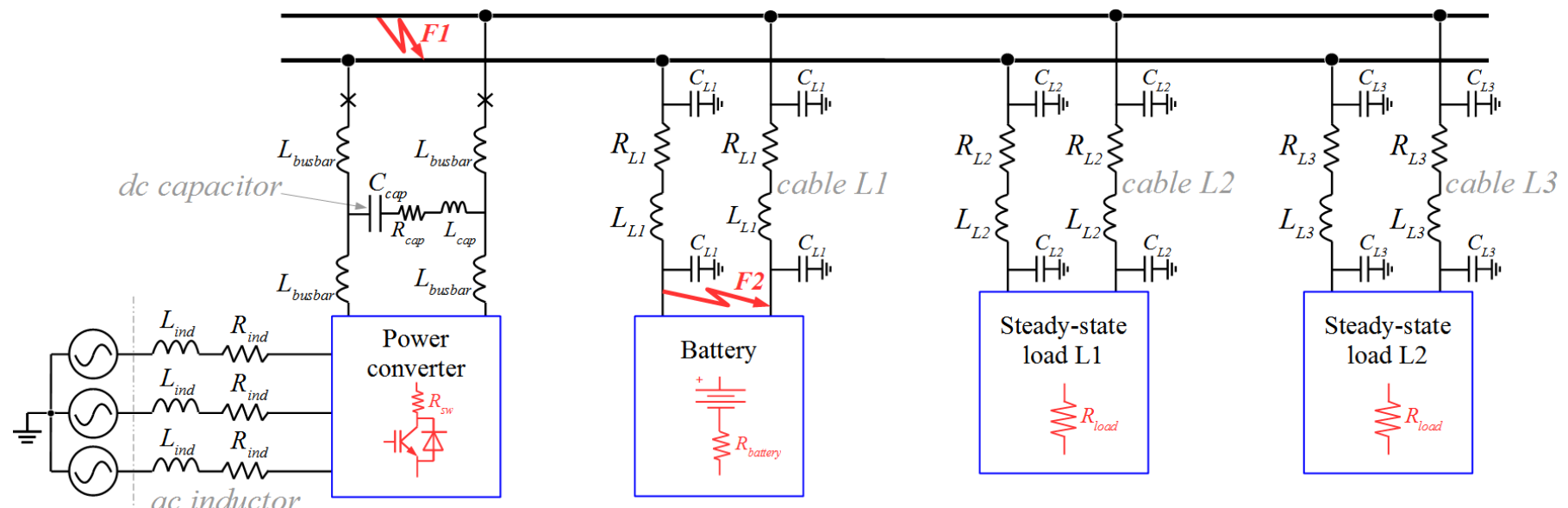

Fig. 1. Detailed network representation of the modelled low voltage dc microgrid. 


\section{POWER CONVERTER DeSIGN FOR LVDC MicRO-GRIDS}

\section{A. Low Voltage DC Micro-Grid}

Fig. 1 illustrates how a low voltage dc micro-grid may incorporate $\mathrm{dc}$ or ac source types. The network in Fig. 1, which is based on a design first described in [1], is used as the platform for the analysis presented within this paper. It includes two dc loads: L1 and L2. The loads are supplied by an ac source, which represents a large electrical machine or an interconnected power system capable of providing stiff voltage characteristics at the point of common coupling (PCC).

During emergency conditions, a micro-grid can be directly supplied from the battery interconnected to the dc distribution bus. Within Fig 1, the main point of interest for this paper is the grid connected ac-dc converter. This will be the sub-system upon which the thermal stress analysis will be conducted.

\section{B. Power Converter Topology}

The examined ac-dc rectifier circuitry from Fig. 2 represents a six-switch voltage source converter, which is commonly used for low voltage applications [14].

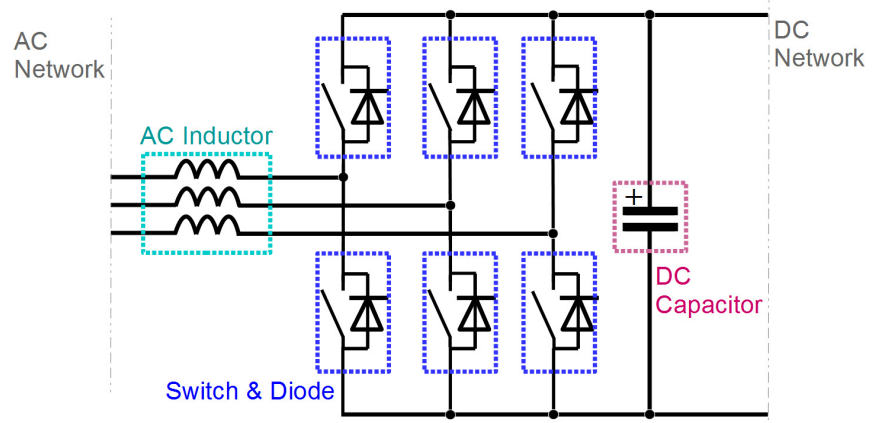

Fig. 2. Main components of six-switch power converter

The presented topology allows decoupling of the dc and ac sides of the electrical system through the common dc link, which simplifies control and switching algorithms.

\section{Power Converter Components}

As with the six-switch converter shown in Fig. 2, other existing voltage source converter topologies are made of switches, diodes, ac inductors and dc capacitors.

The dc capacitor is used to minimize the dc voltage ripple, whereas the ac inductor is used to minimize ac current ripple that appears due to the switching operation. Semiconductor switches are used to control the power flow between ac and dc sides, whereas the diodes rectify input ac power coming from the source.

Each component is vulnerable to two forms of thermal stress, which the paper will classify as:

1) Long-term: During normal operation, where the temperature rise is mainly influenced by ambient conditions, normal system load and the cooling system.

2) Short-term: During fault operation, where the temperature rise is mainly influenced by fault characteristics and fault period.

The components need to be rated both against normal and fault conditions in order to perform reliable operation provided with minimum cost and size penalties.

\section{FAILURE CHARACTERISTICS OF POWER CONVERTER COMPONENTS}

\section{A. Diodes and Switches}

The most common failure mode associated with overheating in semiconductors is bond-wire lift-off [14].

The temperature limit is dictated by the melting temperature, characterized by either the melting point of the semiconductor's mold compound or solder joint. The lower of the two melting points dictates the semiconductor's maximum junction temperature [15-16]. Many commercially available silicon-based high power devices allow operation at junction temperatures up to $T_{j, \max }=150{ }^{\circ} \mathrm{C}$.

The semiconductor switches can be protected against overheating by a block-mode function. This can be initiated using gate driver control circuitry with integrated overtemperature protection. Fig. 3 illustrates an example sensing circuit which utilizes diodes as temperature sensors [17].

While the switches can be protected with a block-mode during dc short circuit faults, there is always a risk of latch-up when device carries a current substantially higher than rated. A latch-up is a failure mode where the switch can no longer be turned off by the gate driver and remains in on-state condition until its rupture. In order to avoid having a latch-up, a soft turn-off switching is required with increased gate resistance. A risk of latch-up can be also minimized by optimizing the doping levels and geometries of the alternating layers within the switch through manufacturing process.

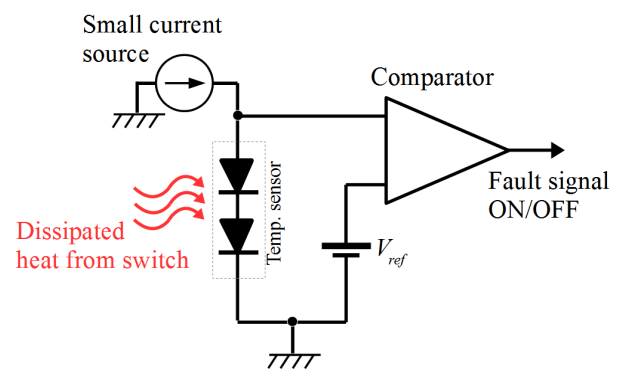

Fig. 3. Sense circuit for over-temperature protection with diode temp. sensors

In case of anti-parallel diodes, unidirectional currents will continue to flow until the converter becomes isolated from the network by the protection system.

\section{B. AC Inductor}

In ac inductor designs, the applied winding insulation materials dictate the maximum permissible hot spot temperature rise. Permissible temperature limits are assigned in accordance with IEC 61558 [18], which varies with the type of insulation system used by manufacturer.

For transient processes, transient temperature rise $\Delta T$ can be characterized by the exponential law defined by the thermal time constant of the component [19]. The same time constant defines the cooling behavior of the component. Overtemperature protection is achieved by isolating or clearing the 
fault before the hot-spot temperature exceeds maximum permissible limit defined in [18].

\section{DC Capacitor}

Under dc fault conditions, stored electrical energy within the dc capacitor is rapidly released and transformed into heat.

Rapid capacitor discharge under the fault conditions results in a characteristic pulse current flow through the capacitor, which can be either aperiodic or damped oscillatory [20].

For thermal analysis, capacitor manufacturers provide maximum hot-spot temperature, thermal resistance and thermal time constant. The thermal time constant can be used to characterize the temperature rise during transient conditions.

Over-temperature short-circuit protection for dc capacitors and semiconductor diodes relies on physical fault isolation (e.g. with the usage of high-speed dc fuses [21]).

\section{DYNAMIC EleCtro-Thermal MODELING}

This paper investigates the thermal impact of the shortcircuit fault currents using dynamic temperature estimation models. These models measure and register the transient temperature rise during the fault period.

\section{A. Diodes and Switches}

The developed temperature-dependent electro-thermal model of a semiconductor calculates the transient temperature rise based on the estimated instantaneous power losses from the output current $i(t)$, voltage $v(t)$, temperature $T_{j(t)}$ and datasheet parameters. Fig. 4 illustrates the top-level flow chart of the developed device electro-thermal model. This proposed power loss modelling approach is consistent with that presented in [22], which is a commonly accepted method for loss evaluation of power semiconductor devices.

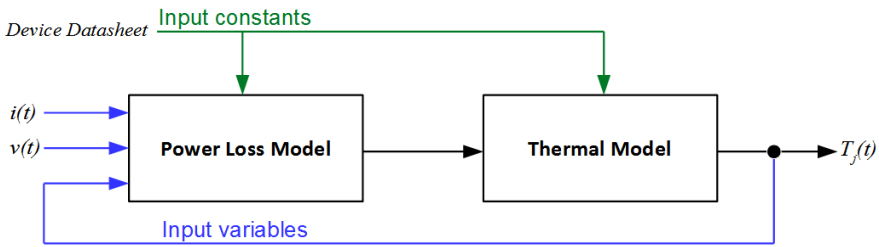

Fig. 4. Top-level flow chart used to estimate junction temperatures.

The Matlab/Simulink [11] implementation of a developed simulation-based IGBT loss model [23] is shown in Fig. 5. Three-dimensional look-up tables are used to determine the dissipated energy values based on the device characterization in manufacturer datasheets.

Loss models of the diodes are of similar design. However, they do not include losses generated during the turn-on, which are considered negligible and are normally neglected [24].

The thermal model of a single device indicates the junction temperature rate of rise $\Delta T(t)$, when the device is subjected to excessive fault current. Fig. 6 illustrates the developed model, in which the thermal impedance from junction to ambient is modelled as a six-layer Foster RC network [25]. Such a network allows accurate estimation of the temperature rise between junction and ambient [26].

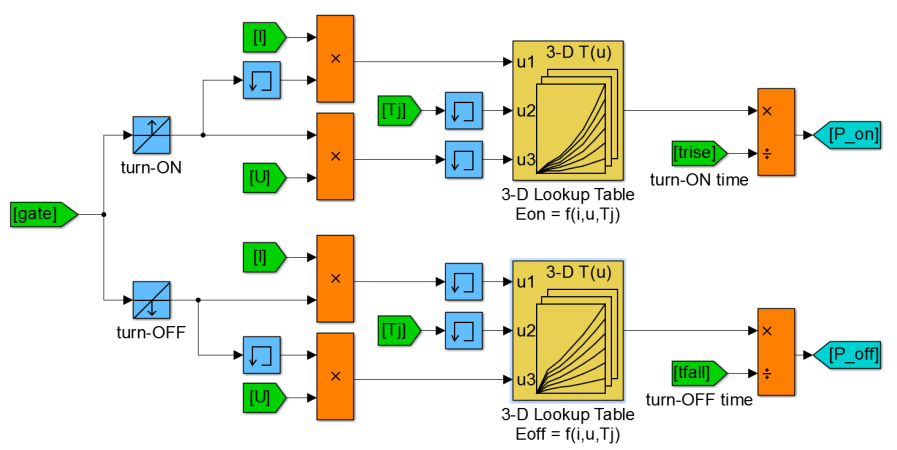

Fig. 5. Matlab/Simulink model for semiconductors switching loss calculation

The thermal resistance $R_{t h}$ will determine the steady state value of junction temperature, and the thermal constant $\tau_{R C}$, which can be calculated from

$$
\tau_{R C}=R_{t h} \cdot C_{t h}
$$

(where $C_{t h}$ is the thermal capacitance and is defined later) will dictate the dynamic change of the junction temperature $T_{j}$. Ambient temperature $T_{a m b}$ is assumed constant during the fault period due to its relatively short duration.

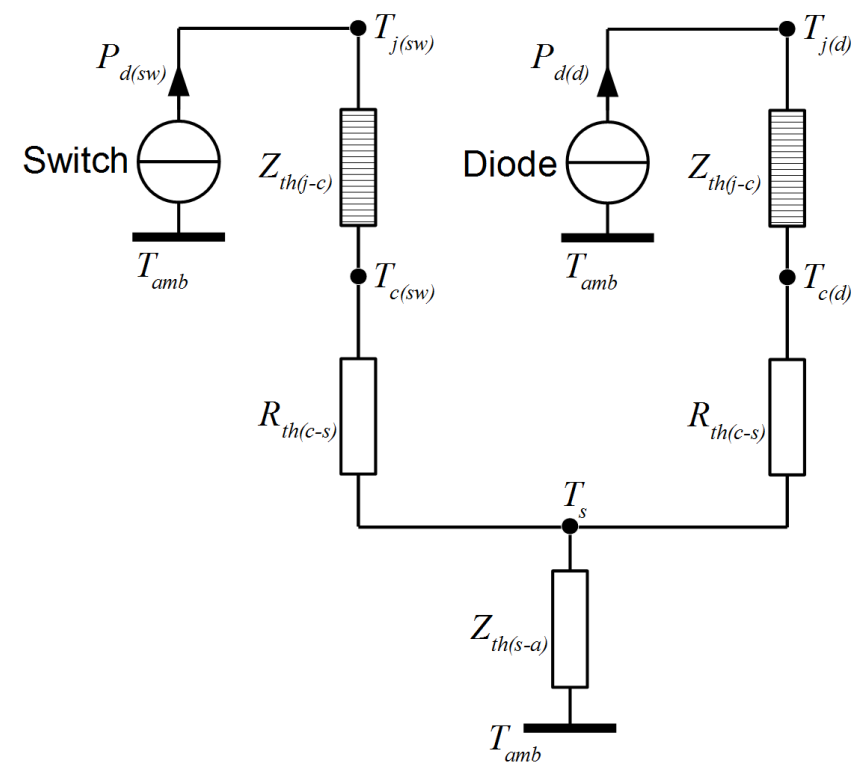

a)

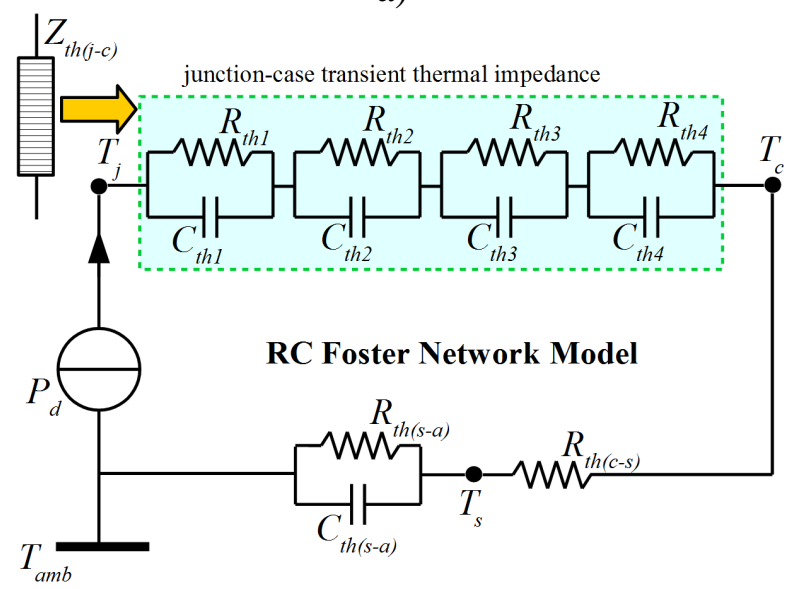

b)

Fig. 6. a) Thermal model of switch and diode used for junction temperature estimation; b) RC Foster network representation $C_{t h}$ 
The parameter values of semiconductor junction-case transient thermal impedance $Z_{t h(j-c)}$ can be found directly from the manufacturer datasheet.

The minimum required thermal resistance of the heatsink $R_{t h(s-a)}$ can be calculated from (2) based on the device nominal power losses $P_{d, N}$

$$
\begin{aligned}
& R_{t h(s-a)}=\frac{\left(T_{C, N}-T_{a m b}\right)}{P_{d, N}}-R_{t h(c-s)} \\
& C_{t h(s-a)}=m_{s} \cdot c_{s}
\end{aligned}
$$

The thermal capacitance $C_{t h(s-a)}$ can be approximated from (3), where $m_{s}$ is mass and $c_{s}$ is the specific heat of the selected heatsink material. Parameter values for $(2,3)$ have been listed in Table I, which provides the specification of the selected heatsink from the manufacturer's datasheet. This and subsequent tables also indicate the price of components. This is the advertised price at the respective reference [27]-[31] at the time of writing and is used for cost estimations in later sections of the paper.

TABLE I

HEATSINK SPECIFICATION: ABL COMPONENTS 177AB2000B [27]

\begin{tabular}{lc} 
Manufacturer & ABL Components \\
\hline Heatsink material & Aluminum \\
\hline Working case temp. $T_{C, N}[\mathrm{C}]$ & 105 \\
\hline Max. thermal resistance $R_{t h(s-a)}[\mathrm{K} / \mathrm{W}]$ & 0.07 \\
\hline Thermal capacitance $C_{t h(s-a)}[\mathrm{W} \cdot \mathrm{s} / \mathrm{K}]$ & $4.31 \mathrm{e} 3$ \\
\hline Weight $m_{s}[\mathrm{~kg}]$ & 5 \\
\hline Specific heat $c_{s}[\mathrm{~J} / \mathrm{kg} \cdot \mathrm{K}]$ & 910 \\
\hline Price $[\$] \quad /$ Size $\left[\mathrm{dm}^{3}\right]$ & $100 / 4.98$ \\
\hline
\end{tabular}

The transient temperature rise $\Delta T(t)$ is estimated from

$$
\Delta T(t)=P_{d}(t) \cdot \sum_{i=1}^{6} R_{t h(i)} \cdot\left(1-e^{-t / R_{t h(i)} \cdot C_{t h(i)}}\right)
$$

Table II lists input values from the semiconductor device manufacturer's datasheet used to model the transient temperature rise.

\begin{tabular}{|c|c|c|c|}
\hline \multicolumn{2}{|l|}{ Parameter } & \multicolumn{2}{|c|}{ Value } \\
\hline Nominal power losses [kW] & $P_{d, N}$ & \multicolumn{2}{|c|}{0.68} \\
\hline Nominal junction temp. & $T_{j, N}$ & \multicolumn{2}{|c|}{125} \\
\hline Maximum junction temp. $\left[{ }^{0} \mathrm{C}\right]$ & $T_{j, \max }$ & \multicolumn{2}{|c|}{150} \\
\hline Ambient temp. $\left[{ }^{0} \mathrm{C}\right]$ & $T_{a m b}$ & \multicolumn{2}{|c|}{40} \\
\hline Case-sink thermal resistance $[\mathrm{K} / \mathrm{W}]$ & $R_{t h(c-s)}$ & \multicolumn{2}{|c|}{0.02} \\
\hline Price $[\$] /$ Size $\left[\mathrm{dm}^{3}\right]$ & & \multicolumn{2}{|c|}{$80 / 0.1$} \\
\hline $\begin{array}{l}\text { Switch thermal impedance }[\mathrm{K} \cdot \mathrm{s} / \mathrm{W}] \\
\text { RC layer factors }\end{array}$ & $Z_{t h(j-c)}$ & $\begin{array}{l}R_{t h l}=8.9 \\
R_{t h 2}=110.0 \\
R_{t h 3}=74.0 \\
R_{t h 4}=17.0\end{array}$ & $\begin{aligned} C_{t h l} & =2.0 \mathrm{e}-4 \\
C_{t h 2} & =2.2 \mathrm{e}-4 \\
C_{t h 3} & =8.8 \mathrm{e}-4 \\
C_{t h 4} & =3.9 \mathrm{e}-2\end{aligned}$ \\
\hline $\begin{array}{l}\text { Diode thermal impedance }[\mathrm{K} \cdot \mathrm{s} / \mathrm{W}] \\
\mathrm{RC} \text { layer factors }\end{array}$ & $Z_{t h(j-c)}$ & $\begin{array}{l}R_{t h l}=141.0 \\
R_{t h 2}=135.2 \\
R_{t h 3}=84.9 \\
R_{t h 4}=38.9\end{array}$ & $\begin{aligned} C_{t h l} & =3.4 \mathrm{e}-4 \\
C_{t h 2} & =1.2 \mathrm{e}-4 \\
C_{t h 3} & =1.3 \mathrm{e}-3 \\
C_{t h 4} & =2.3 \mathrm{e}-4\end{aligned}$ \\
\hline
\end{tabular}

TABLE II

SWITCH AND Diode SPECIFICATION: INFINEON BSM 150 GB 60 DLC [28]

\section{B. AC Inductor and DC Capacitor}

The transient temperature rise in inductive or capacitive components can be approximated by an equivalent one-layer Foster RC network presented in Fig. 7.

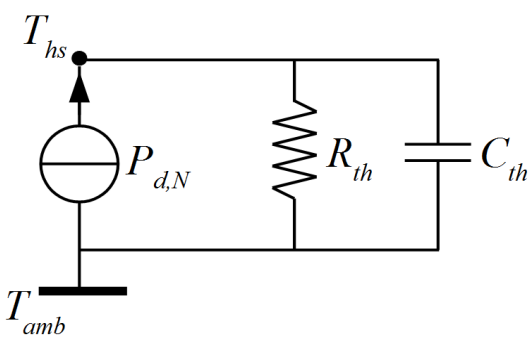

Fig. 7. Thermal model used for hot-spot temperature estimation in ac inductors and dc capacitors

For an inductor design, a classical thermal model [19] can be used to calculate the steady-state equivalent thermal resistance of an inductor $R_{\mathrm{th}}$ as a function of the dissipated core (magnetic) and winding (conduction) losses $P_{\text {losses }}$

$$
R_{t h}=\frac{\Delta T}{P_{\text {losses }}},
$$

where $\Delta T$ represents the temperature rise from ambient to insulation layer.

The total thermal capacitance $C_{t h}$ of the inductor can be approximated from [19]

$$
\begin{aligned}
& C_{t h} \cong C_{t h(\text { winding) }}+C_{\text {thl(core) }}=c_{\text {winding }} \cdot \delta_{\text {winding }} \cdot V_{\text {winding }}+ \\
& c_{\text {core }} \cdot \delta_{\text {core }} \cdot V_{\text {core }}
\end{aligned}
$$

In accordance with Table III, calculated values of specific heat capacitances $(c \cdot \delta)$ for the winding and for the magnetic core materials are close to each other.

TABLE III

PARAMETERS OF THERMAL MODEL FOR AC INDUCTOR [29]

\begin{tabular}{lc} 
Manufacturer & MTE \\
\hline Core material $(3.1 \%$ sillicon content) & CRGO Sillicon Steel M-6 \\
\hline Core losses [W/kg] & 1.1 \\
\hline Windings material & Copper \\
\hline Core specific heat $c_{\text {core }}[\mathrm{J} / \mathrm{kg} \cdot \mathrm{K}]$ & 460 \\
\hline Windings specific heat $c_{\text {winding }}[\mathrm{J} / \mathrm{kg} \cdot \mathrm{K}]$ & 383 \\
\hline Core density $\delta_{\text {core }}\left[\mathrm{kg} / \mathrm{m}^{3}\right]$ & 7417 \\
\hline Windings density $\delta_{\text {winding }}\left[\mathrm{kg} / \mathrm{m}^{3}\right]$ & 8954 \\
\hline
\end{tabular}

In general, the thermal capacitance $C_{t h}$ can be determined by the total volume of inductor $V_{\text {total }}$.

$$
V_{\text {total }}=V_{\text {winding }}+V_{\text {core }}
$$

For capacitor designs, manufacturers typically provide the thermal time constant, the value of which can be used to calculate $C_{t h}$ from (1) based on the previously calculated thermal resistance $R_{t h}$

$$
R_{t h}=\frac{\Delta T}{P_{d, N}}=\frac{T_{h s, N}-T_{a m b}}{P_{d, N}}
$$

where $\Delta T$ is the steady temperature rise between surface $T_{h s, N}$ and ambient $T_{a m b}$.

With known RC thermal network constants, the transient temperature rise $\Delta T(t)$ can be estimated from [19]

$$
\Delta T(t)=P_{d}(t) \cdot R_{t h} \cdot\left(1-e^{-t / R_{h h} \cdot C_{t h}}\right)
$$

Table IV lists input values from manufacturer datasheets, which are used to model the temperature rise in ac inductors and dc capacitors. 
TABLE IV

SPECIFICATION OF AC INDUCTOR AND DC CAPACITORS [30]-[31]

\begin{tabular}{lcc} 
& AC Inductor & DC Capacitor \\
\hline Manufacturer & MTE & EPCOS-TDK \\
\hline Nominal rating $I_{N}[\mathrm{~A}]$ & 1000 & 65 \\
\hline Nominal hot-spot temp. $T_{h s, N}[\mathrm{C}]$ & 180 & 70 \\
\hline Maximum hot-spot temp. $T_{h s, \max }[\mathrm{C}]$ & 200 & 85 \\
\hline Ambient temp. $T_{a m b}[\mathrm{C}]$ & 45 & 30 \\
\hline Nominal losses $P_{d, N}[\mathrm{~kW}]$ & 1.30 & $10.8 \mathrm{e}-3$ \\
\hline Core/dielectric losses $[\mathrm{kW}]$ & 0.165 & $6.13 \mathrm{e}-3$ \\
\hline Thermal resistance $R_{t h}[\mathrm{~K} / \mathrm{W}]$ & 0.104 & 3.8 \\
\hline Thermal capacitance $C_{t h}[\mathrm{~W} \cdot \mathrm{s} / \mathrm{K}]$ & $2.88 \mathrm{e} 5$ & $1.14 \mathrm{e} 3$ \\
\hline Size $\left[\mathrm{dm}^{3}\right]$ & 84.3 & 0.74 \\
\hline Weight $[\mathrm{kg}]$ & 152.3 & 0.88 \\
\hline Price $[\$]$ & 6,307 & 90
\end{tabular}

\section{DC FAULT SCENARIOS}

\section{A. System Description}

The transient temperature rise of the power converter components is investigated using a detailed transient model of the network illustrated in Fig. 1.

Parameters for each component are listed in Table V. During normal operation, the converter output is regulated using a rotating dq0 reference frame based controller to provide $320 \mathrm{~kW}$ of active power $P_{a c}=320 \mathrm{~kW}$ into the dc network. The switches are continuously PWM modulated at fixed switching frequency of $f_{s w}=2.7 \mathrm{kHz}$, which is limited by the nominal junction temperature $T_{j, N}=125{ }^{\circ} \mathrm{C}$.

TABLE V

SYSTEM PARAMETERS OF LOW VOLTAGE DC MICROGRID [1]

\begin{tabular}{lcccc}
\multicolumn{1}{c}{ Component } & Data & $\mathbf{R}$ & $\mathbf{L}$ & C \\
\hline ac inductor (x1) & $1000 \mathrm{~A}$ & $0.38 \mathrm{~m} \Omega$ & $43 \mu \mathrm{H}$ & \\
dc capacitor (x9) & $65 \mathrm{~A}$ & $1.1 \mathrm{~m} \Omega$ & $40 \mathrm{nH}$ & $0.44 \mathrm{mF}$ \\
Semiconductor (x15) & $150 \mathrm{~A} / 2.7 \mathrm{kHz}$ & $1 \mathrm{~m} \Omega$ & $40 \mathrm{nH}$ & \\
Load (x2) & $160 \mathrm{~kW}$ & $1 \Omega$ & - & \\
Battery (x1) & $45 \mathrm{Ah} / 100 \mathrm{~ms}$ & $76 \mathrm{~m} \Omega$ & - & \\
Cables (L1, L2) & $100 \mathrm{~m}$ & $0.64 \Omega / \mathrm{km}$ & $0.34 \mathrm{mH} / \mathrm{km}$ & $0.1 \mu \mathrm{F} / \mathrm{km}$ \\
Cable (L3) & $50 \mathrm{~m}$ & $0.64 \Omega / \mathrm{km}$ & $0.34 \mathrm{mH} / \mathrm{km}$ & $0.1 \mu \mathrm{F} / \mathrm{km}$ \\
ac network 50 Hz & $320 \mathrm{kVA} / 190 \mathrm{~V}$ & $0.01 \mathrm{pu}$ & $0.1 \mathrm{pu}$ & \\
dc network / busbar & $320 \mathrm{~kW} / 400 \mathrm{~V}$ & & $20 \mathrm{nH}$ & \\
\hline
\end{tabular}

According to Table $\mathrm{V}$, a total current is shared across five identical parallel-connected semiconductor switches. In order to ensure a uniform current sharing between the modules and maintain a minimal de-rating factor, following technical measures need to be considered [32]:

- Symmetric construction of the power circuit with identical connection impedance values for each paralleled module.

- Homogenous cooling with the same inlet temperature of the cooling medium for paralleled module heatsinks (to maintain a close matching junction temperatures and to avoid possible thermal runaway).

- Common gate-voltage supply and gate driver circuit.

- Usage of common-mode chokes (to mitigate effect of unequal gate driver connection impedance) and active clamps (to mitigate effect of unequal stray inductances).
The two critical fault locations highlighted in Fig. 1 are considered in order to determine the maximum thermal stress on converter components.

Faults F1 and F2 are applied at 0.5 s. Based on the dc capacitor discharge characteristics from [22], fault F1 provides a damped oscillatory response and fault F2 provides an aperiodic response. In order to determine protection system requirements for a power converter components,

The following sub-sections will first illustrate the electrical system response to these faults before the electrothermal characteristics of the converter components are investigated.

Due to the saturation effect, during the short-circuit period the inductance of an ac reactor changes quasi-linearly in accordance with the linearity curve from Fig. 8, which is obtained from the manufacturer's datasheet [33].

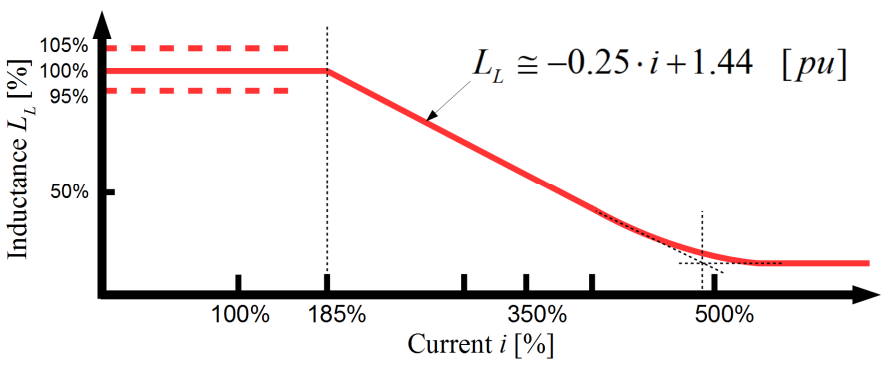

Fig. 8.AC inductor saturation curve of the nominal inductance changes

\section{B. Damped Oscillatory Fault F1 (Fig. 8)}

Fig. 9 shows the total fault current and its contributing components (within the close-up of the initial transient inset on the right hand side of Fig. 8) for a short circuit fault at location F1. The capacitor dictates the maximum peak fault value of $81.9 \mathrm{kA}$ after $26 \mu$ s of fault occurrence. The peak fault current level is limited by the parasitic inductance $L_{c a p}$ and resistance $R_{\text {cap }}$ of the dc capacitor and stray inductances $L_{\text {busbar }}$ of a dc busbar.
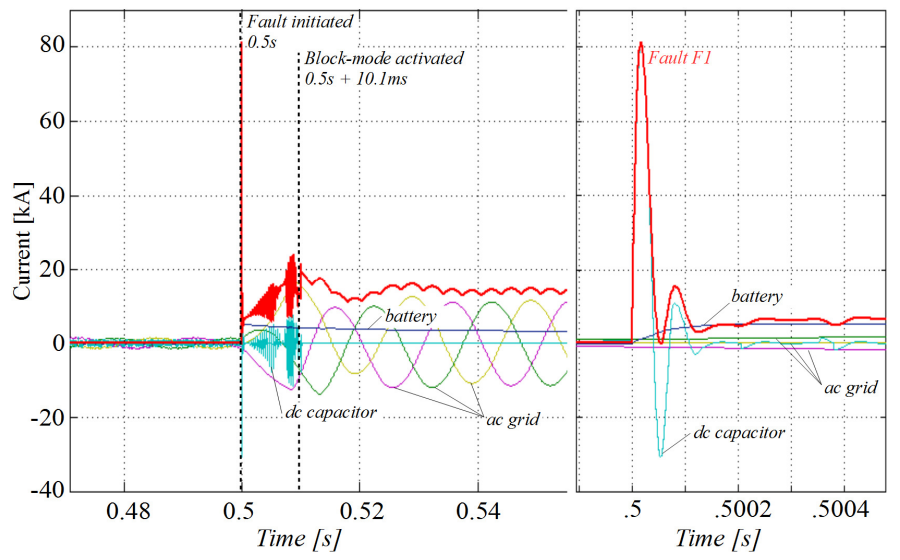

Fig. 9. Damped oscillatory fault F1 after $0.5 \mathrm{~s}$ in low voltage microgrid

The oscillating characteristics of a dc fault current results in bidirectional flow of the current. During the negative peak of $30 \mathrm{kA}$, which is reached at $53 \mu \mathrm{s}$ a fault current flows through parallel branches created by series-connected diodes of a converter. As a consequence, the diodes are thermally stressed within the very first microseconds of fault occurrence by the 
energy coming from the dc capacitor. This energy makes the diodes exceed thermal limits before switches are blocked, as illustrated in Fig. 12.

After the capacitors rapid discharge at $0.5 \mathrm{~s}+100 \mu \mathrm{s}$, the interconnected battery provides the largest contribution where the maximum fault current is $5 \mathrm{kA}$. Due to the overtemperature, the block-mode of a power converter is activated after $10.1 \mathrm{~ms}$ of fault occurrence.

The current contribution from the battery is kept constant, as it is being continuously fed by the ac network. After $0.51 \mathrm{~s}$, the main fault contribution comes from ac grid and the steady value of the dc fault current becomes $14.55 \mathrm{kA}$ at $0.54 \mathrm{~s}$, which is 18 times higher than the nominal value.

\section{Aperiodic Fault F2 (Fig. 9)}

Fig. 10 shows the total fault current and its contributing components for a short circuit fault at location F2. From this fig., it can be observed that at the initial stage of the fault occurrence, the dominant contribution comes from the dc battery, where current increases exponentially. After $25 \mathrm{~ms}$, the battery discharges and the collapsed dc voltage results in increased ac current flow from the grid.

At $0.69 \mathrm{~s}$, the junction temperature of semiconductor switches reaches $150{ }^{\circ} \mathrm{C}$. As a consequence, the block-mode of the converter activates and all semiconductor switches are turned off. It results in an increased current flowing from the battery and a reduced current flowing through the capacitor. In accordance with the inductor time constant, ac currents keep increasing exponentially until they reach steady state level of $13.55 \mathrm{kA}$ at $0.92 \mathrm{~s}$.

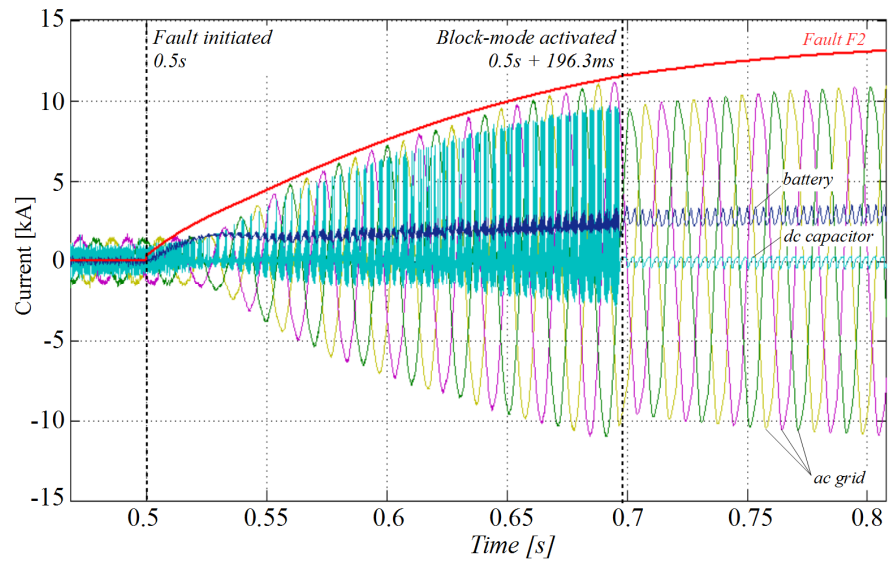

Fig. 10. Aperiodic fault F2 after $0.5 \mathrm{~s}$ in low voltage de microgrid.

\section{DYNAMIC ELECTRO-THERMAL ANALYSIS}

\section{A. Diodes and Switches}

Complex dynamic electro-thermal models are used for the semiconductors in order to accurately represent the dissipated power from the $2.7 \mathrm{kHz}$ switching operation of the converter.

Fig. 11 and Fig. 12 accordingly illustrate the registered junction temperatures and currents for each individual semiconductor switch and diode during fault F1. During normal operation, semiconductor switches operate below $T_{j}=$ $125^{\circ} \mathrm{C}$, whereas the diodes operate at $T_{j}=60{ }^{\circ} \mathrm{C}$.
The inherent blocking capability of the converter prevents the semiconductor switches from becoming damaged due to over-temperature. However, the diodes remain vulnerable and continue to conduct fault current even after activating the block-mode. In this case, the estimate diode junction temperature $T_{j}$ exceeds maximum permissible $T_{j, \max }=150{ }^{\circ} \mathrm{C}$ value after $4.5 \mathrm{~ms}$ and temperature continues to increase until it reaches a peak of $T_{j}=223{ }^{\circ} \mathrm{C}$ at $15.1 \mathrm{~ms}$.

After approx. $60 \mathrm{~ms}$ of fault occurrence, the temperature decreases to remain steady at $150{ }^{\circ} \mathrm{C}$ level, which is the result of the continuous flow of current from the ac grid. The temperature rate of change is determined by transient thermal time constant $\tau_{R C}$ and amount of energy released from rapid discharge of dc capacitor.

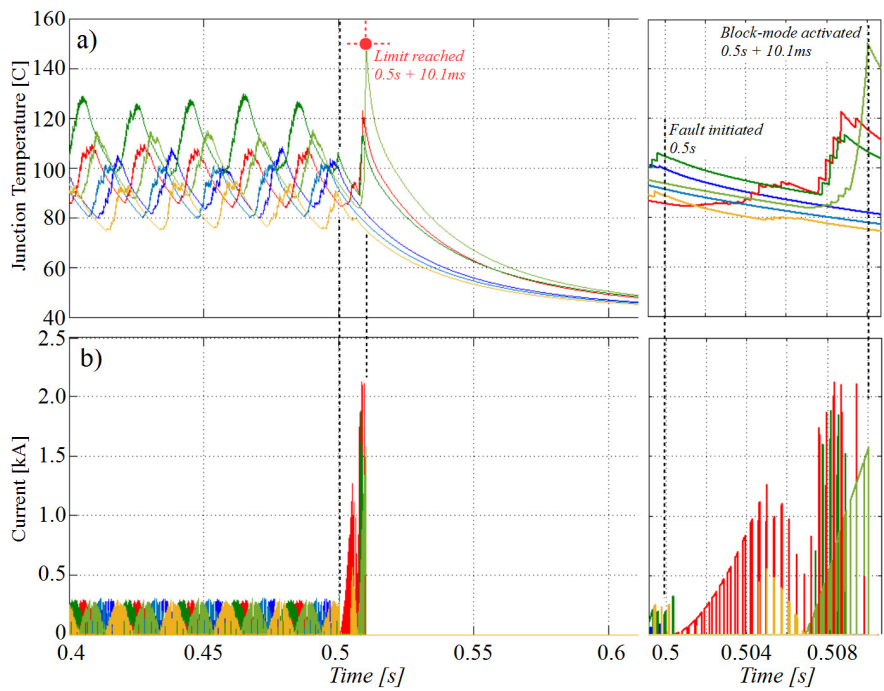

Fig. 11. a) Junction temperature variations $T_{j}(t)$ under fault $\mathrm{F} 1$; b) Currents distribution over semiconductor switches.

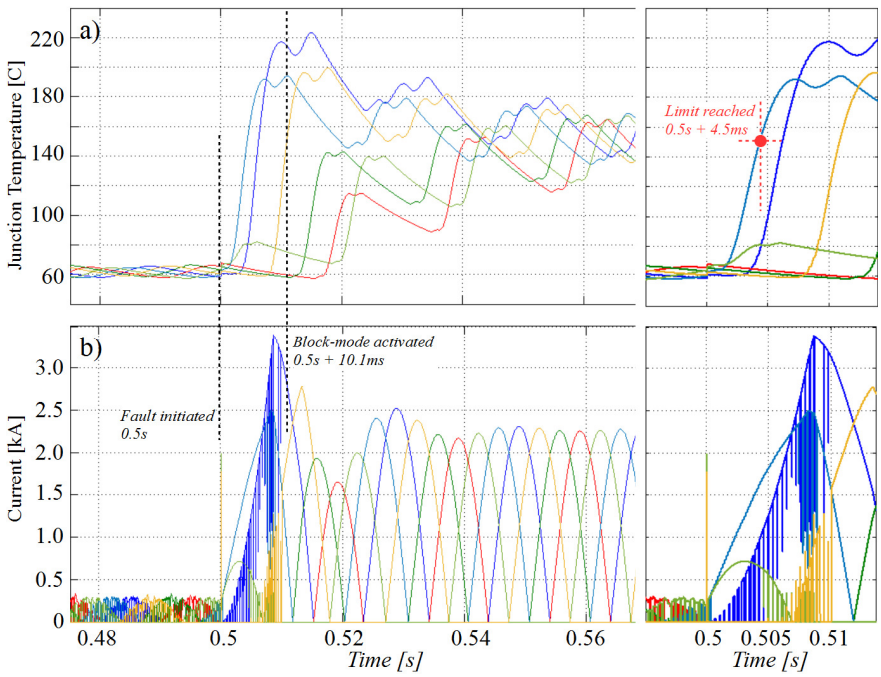

Fig. 12. a) Junction temperature variations $T_{j}(t)$ under fault $\mathrm{F} 1$; b) currents distribution over semiconductor diodes.

Thermal impact on semiconductors during aperiodic fault F2 is visualized in Fig. 13 and Fig. 14. It can be seen that the diodes will not suffer thermal stress, as the maximum junction temperature is $T_{j, \max }=134{ }^{\circ} \mathrm{C}$ during entire fault period. However, semiconductor switches must be isolated after 196.3 ms, which prevents the continuous fault-tolerant operation. 


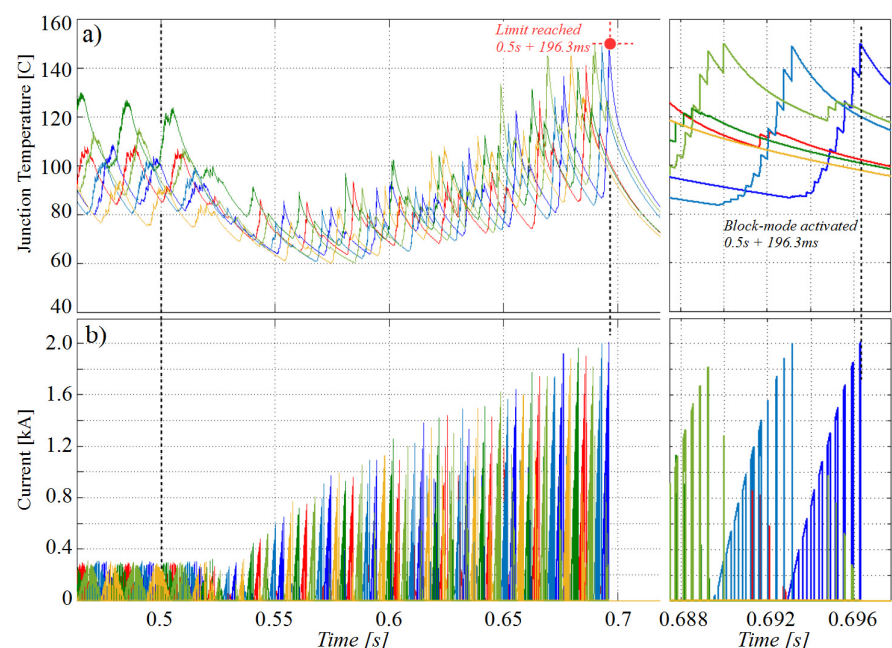

Fig. 13. a) Junction temperature variations $T_{j}(t)$ under fault $\mathrm{F} 2$; b) currents distribution over semiconductor switches.
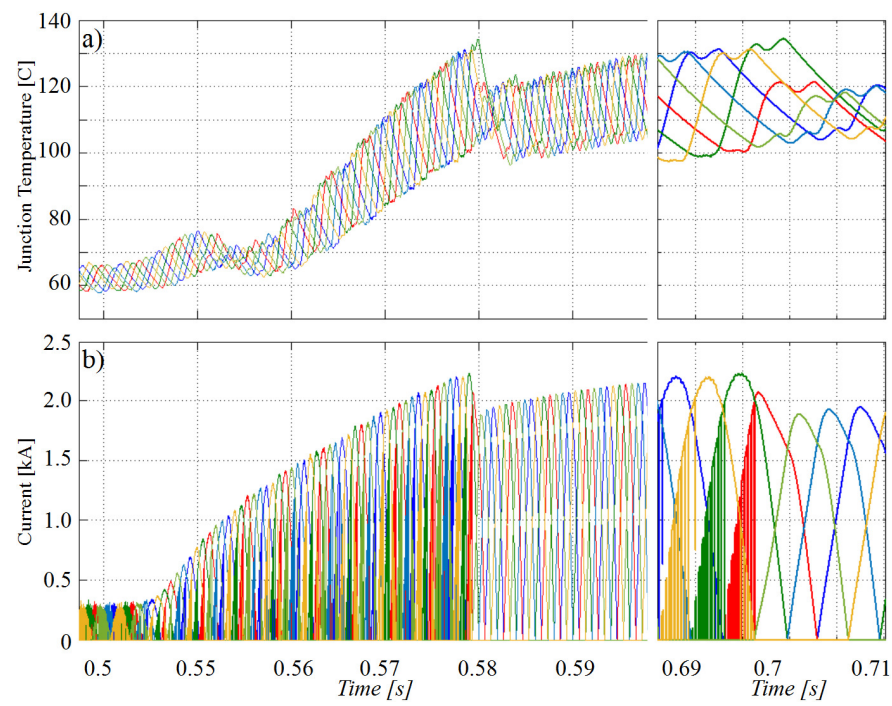

Fig. 14. a) Junction temperature variations $T_{j}(t)$ under fault $\mathrm{F} 2$; b) currents distribution over semiconductor diodes.

\section{B. AC Inductor \& DC Capacitor}

Fig. 15 illustrates how the transient temperature increases for the ac inductor and dc capacitors during faults F1 and F2 (note that both faults induce a near-identical temperature rise in these passive components).
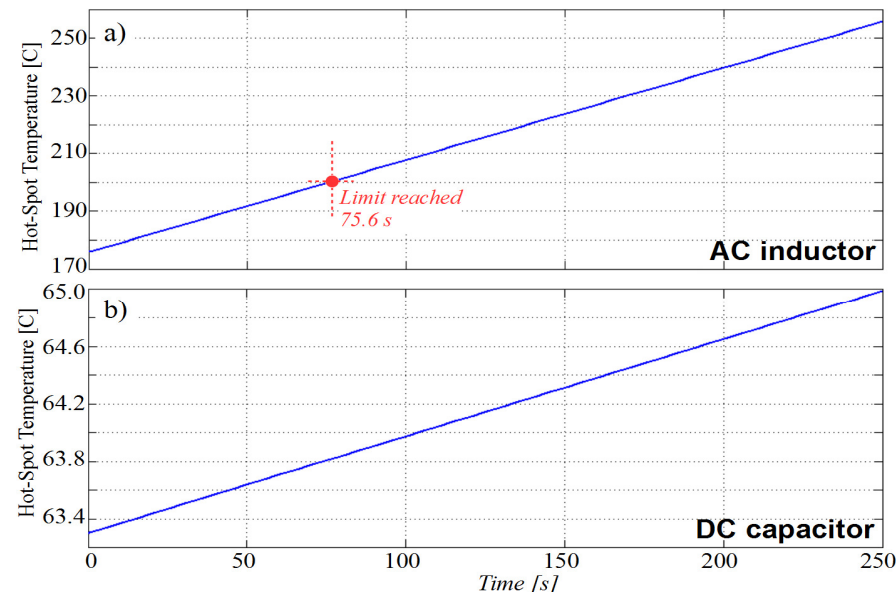

Fig. 15. Hot-spot temperature variations $T_{h s}(t)$ under faults F1 and F2: a) in ac inductor; b) in dc capacitors.
Prior to the fault, the hot-spot temperature of the ac inductor is $T_{h s}=176{ }^{\circ} \mathrm{C}$. The registered temperature exceeds maximum permissible limit $T_{h s, \max }=200{ }^{0} \mathrm{C}$ after $75.6 \mathrm{~s}$ for faults F1 and F2.

The hot spot pre-fault temperature of dc capacitor is 63.3 ${ }^{0} \mathrm{C}$. After 250s duration of faults F1 and F2, the temperature of the dc capacitors increases by only approximately $1.7^{\circ} \mathrm{C}$. As a result the dc capacitor temperature

According to the Fig. 12, ac inductor and dc capacitors are not vulnerable to the short-term thermal stress caused by dc short-circuit current, since their thermal time constants are much larger than the time constants of semiconductors.

\section{DC FAult PROTECTION CONSIDERATIONS OF POWER CONVERTER COMPONENTS}

\section{A. Impact of Ambient Conditions}

Table VI presents the minimum protection operating times for a range of ambient temperatures $T_{a m b}=0-60{ }^{\circ} \mathrm{C}$, when the components are rated only for operation under normal conditions.

The total cost of dc capacitors and semiconductors from [27], [28] and [31] is estimated by adjusting the required minimum number of parallel-connected units. In this manner, the thermal design is constant and the operating temperature can be decreased by reducing the nominal device power losses $P_{d, N}$. When compared with the generalized component cost models available in [34], the total cost of paralleled-connected components do not exceed $10 \%$ of a predicted value obtained from the models.

TABLE VI

PROTECTION OPERATING TIME REQUIREMENTS FOR CONVERTERS DESIGNED FOR DIFFERENT AMBIENT CONDITIONS

\begin{tabular}{|c|c|c|c|c|c|c|c|c|}
\hline \multicolumn{2}{|c|}{ Ambient temperature $\left[{ }^{0} \mathrm{C}\right]$} & 0 & 10 & 20 & 30 & 40 & 50 & 60 \\
\hline \multirow{3}{*}{$\begin{array}{l}\text { Component } \\
\text { count }\end{array}$} & semiconductors & 9 & 12 & 12 & 12 & 15 & 15 & 18 \\
\hline & dc cap & 5 & 6 & 6 & 7 & 9 & 12 & 45 \\
\hline & ac inductor & 1 & 1 & 1 & 1 & 1 & 1 & 1 \\
\hline \multicolumn{2}{|c|}{ Estimated cost $[\mathrm{x} 1000 \$]$} & 8.4 & 9.0 & 9.0 & 9.1 & 9.8 & 10.1 & 13.6 \\
\hline \multicolumn{2}{|c|}{ Protection op. time [ms] } & 4.14 & 5.02 & 3.78 & 3.68 & 4.51 & 6.21 & 8.83 \\
\hline
\end{tabular}

The minimum protection operating times are a function of the number of parallel-connected diodes. Table VI shows that in order to remain within the current ratings of the diodes, the fault protection system unit should detect and isolate the fault in less than $4.14 \mathrm{~ms}$ at $T_{a m b}=0{ }^{\circ} \mathrm{C}$ and $8.83 \mathrm{~ms}$ at $T_{a m b}=60{ }^{\circ} \mathrm{C}$. As a result, the protection system requirements may vary with the change of ambient temperatures $\Delta T_{a m b}$. It also highlights that although the converter is operating closer to its thermal limit at higher ambient temperature, the need to include additional devices for stable operation during steady state at these ambient temperatures means that the converter is better equipped to carry excess current during fault conditions.

In order to determine the optimal operating speed for the $\mathrm{dc}$ fault protection unit, the current rating of converter components can be further translated into an actual cost in order to economically justify the selection of the dc fault 
protection system.

Fig. 16 presents the total cost of semiconductors, which is correlated with the ranges of maximum fault breaking times $t_{\text {break }}$. This highlights that for ambient temperatures below $T_{a m b}$ $<50{ }^{\circ} \mathrm{C}$, an approximate cost savings of $20 \%$ can be achieved if the protection system is capable of clearing the fault in $t_{\text {break }}$ $<2.5 \mathrm{~ms}$. Of course, this would need to be traded off against the cost of such a protection scheme when considering the full system design.

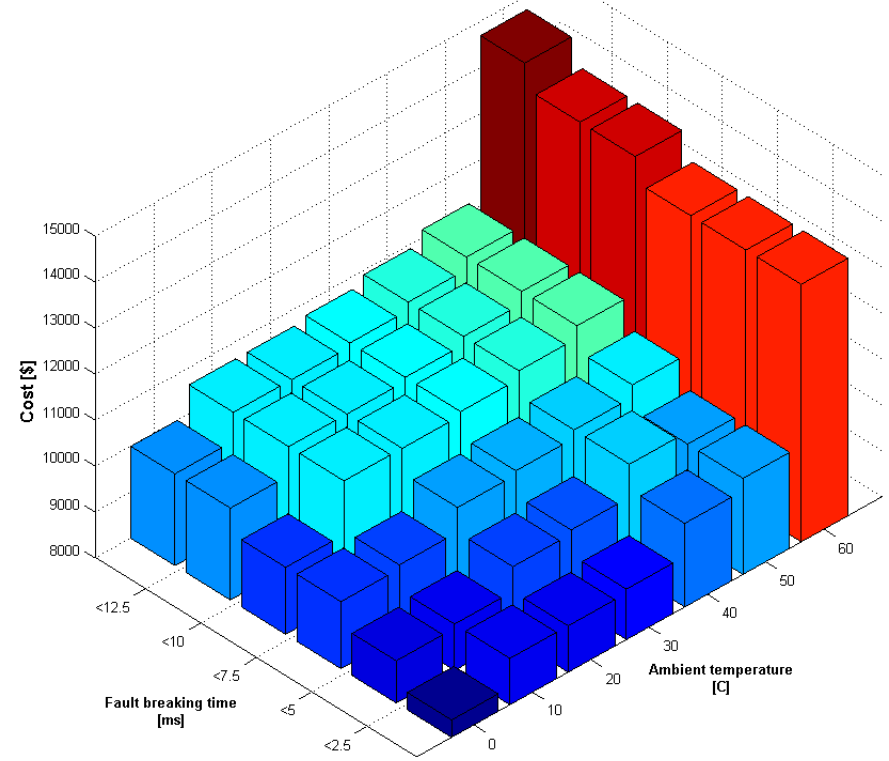

Fig. 16 Approximate cost of the required power converter for reliable operation under fault and ambient conditions.

For ambient temperatures above $T_{a m b}>50{ }^{0} \mathrm{C}$, a high number of parallel-connected dc capacitors is required to maintain an operation within the thermal limits. This increases the overall cost of a converter by $45 \%$. In this case, a moderate protection system operating in $t_{\text {break }}<7.5 \mathrm{~ms}$ can reduce such additional cost down to $30 \%$.

\section{B. Impact of Latch-up Failure Mode}

A high currents flowing through the semiconductor switches during the short-circuit period may result in their static latch-up and loss of switching control. In this scenario, the block-mode cannot be effectively activated, as the latchedup switches will remain in on-state mode and generate conduction losses until the converter is disconnected from the supply. This will impact the thermal characteristics of the power devices, and consequently the protection system operating requirements.

Table VII presents the obtained values of required minimum fault breaking times $t_{\text {break }}$ for $T_{a m b}=40{ }^{\circ} \mathrm{C}$ and for different current levels above the Short Circuit Safe Operating Area (SCSOA), above which a latch-up may occur. The results are performed for a nominal component count listed in Table VI.

Due to rapid discharge of dc capacitors, the currents in switches exceed latch-up limits before triggering the overtemperature protection.
TABLE VII

PROTECTION OPERATING TIME REQUIREMENTS FOR CONVERTERS WITH LATCHUP POWER DEVICES

\begin{tabular}{c|c|c|c|c|c|c}
\multicolumn{2}{l|}{ Latch-up current $i_{\text {latch }}[\mathrm{pu}]$} & No latch-up & $15 \mathrm{pu}$ & $10 \mathrm{pu}$ & $5 \mathrm{pu}$ & $3 \mathrm{pu}$ \\
\hline \multicolumn{2}{l|}{ Latch-up time $[\mathrm{ms}]$} & $\mathrm{n} / \mathrm{a}$ & $\mathrm{n} / \mathrm{a}$ & 3.8 & 1.9 & 1.4 \\
\hline \multirow{2}{*}{$\begin{array}{c}\text { Protection op. } \\
\text { time } t_{\text {break }}[\mathrm{ms}]\end{array}$} & Latch-up switch & $\mathrm{n} / \mathrm{a}$ & $\mathrm{n} / \mathrm{a}$ & 4.1 & 3.1 & 3.2 \\
\cline { 2 - 8 } & Diode & 4.51 & 4.51 & 7.33 & 7.53 & 7.42
\end{tabular}

If a latch-up occurs at low current levels below $i_{\text {latch }}<10$ $\mathrm{pu}$, the diodes allow a longer time frame of $7 \mathrm{~ms}$ for fault clearance in comparison to a latch-up free operation. This is due to the parallel short-circuit commutation path formed within a converter phase leg. A path is formed by a latch-up switch, which effectively splits the current from the ac network flowing between the switch and the series-connected diode

A more vulnerable than diodes are the switches that experienced latch-up and generate excessive conduction losses. In order to avoid their rupture, the protection system has to isolate latch-up switches in $t_{\text {break }}<3 \mathrm{~ms}$.

Fig. 17 presents the minimum number of additional parallel-connected semiconductors required due to latch-up. The number will vary in accordance with the operating speed of a protection system.

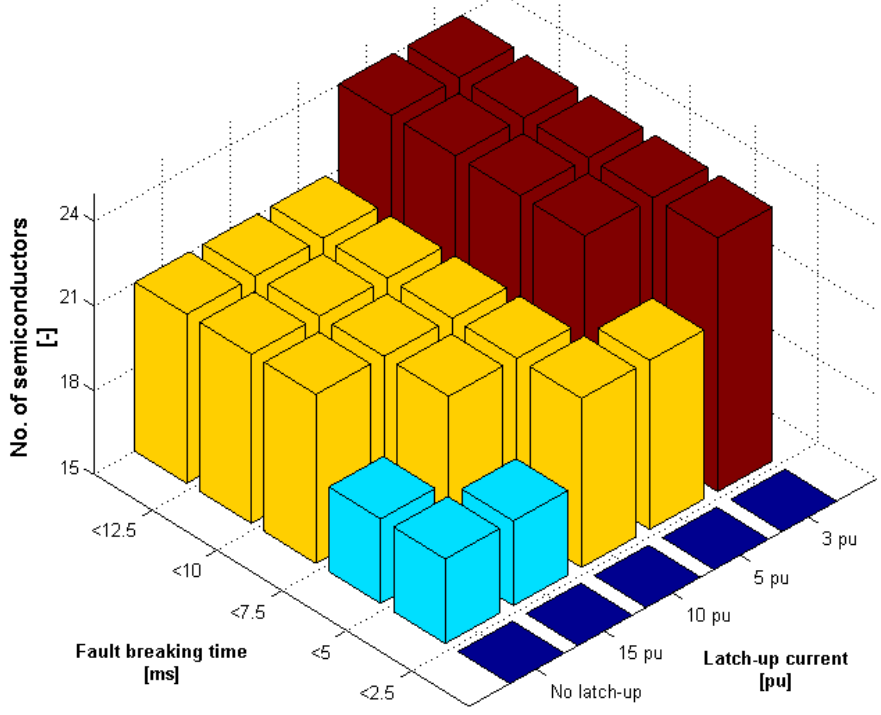

Fig. 17 Minimum number of semiconductors required for safe operation during different latch-up failure modes.

The worst conditions occur for a latch-up at $3 \mathrm{pu}$ of a device rated current $\left(i_{\text {latch }}=3 \cdot I_{N}=450 \mathrm{~A}\right)$. In this scenario, a fast-acting protection is required with $t_{\text {break }}<2.5 \mathrm{~ms}$. Otherwise, additional semiconductors are required, which account for $16 \%$ of a total cost. If a device has a high latch-up free operation up to $10-15 \mathrm{pu}$ and $t_{\text {break }}>2.5 \mathrm{~ms}$, total cost increases by $5 \%$.

\section{Impact of Fault Current Limiters}

A reliable fast-acting fault current limiter can be considered to optimize a design of fault protection scheme in terms of cost and operating speed. In this paper, impact of fault current limiter on system performance is examined based on current 
limiting level. The simulation results have shown, that four current limiting levels $I_{\text {limit }(\%)}$ can be identified and associated to different operating conditions. This has been illustrated in Table IV with obtained ranges for current limiting levels, when the fault current limiter is activated immediately after the presence of a fault, which corresponds to the usage of solid state limiters. The results are performed for a nominal component count listed in Table VI for $T_{a m b}=40{ }^{0} \mathrm{C}$.

With fault current limiters capable of a suppressing a shortcircuit current up to $I_{\text {limit }(\%)}=40 \%$ of its maximum value, no effect has been observed on a dynamic temperature characteristics of power devices. The protection system operating times will remain the same and they will dictate the required minimum number of components to withstand fault conditions.

TABLE VIII

EFFECT OF SOLID STATE FAULT CURRENT LIMITERS ON PROTECTION SYSTEM OPERATING REQUIREMENTS

\begin{tabular}{c|c|c}
$\boldsymbol{I}_{\text {limit }}(\%)$ & Effect & Description \\
\hline$<40 \%$ & $\begin{array}{c}\text { Fast-acting } \\
\text { protection required }\end{array}$ & $\begin{array}{c}\text { No significant effect is observed on the } \\
\text { thermal loading of power devices }\end{array}$ \\
\hline $40-60 \%$ & $\begin{array}{c}\text { Slow-acting } \\
\text { protection required }\end{array}$ & $\begin{array}{c}\text { Converter is set to block-mode and diodes } \\
\text { need to be disconnected after appr. 100ms }\end{array}$ \\
\hline $60-80 \%$ & $\begin{array}{c}\text { Block-mode } \\
\text { activated }\end{array}$ & $\begin{array}{c}\text { Converter is set to block-mode, but diodes } \\
\text { can remain interconnected }\end{array}$ \\
\hline$>80 \%$ & $\begin{array}{c}\text { Continuous } \\
\text { operation }\end{array}$ & $\begin{array}{c}\text { Converter maintains continuous fault- } \\
\text { tolerant operation }\end{array}$
\end{tabular}

If a fault current limiter has a higher limiting factor $I_{\text {limit } \%)}>$ $40 \%$, a fast-acting fault protection system that operates within a few milliseconds is no longer required. When more effective fault limitation is applied at $I_{\text {limit }(\%)}=80 \%$, power converter will maintain a continuous fault-tolerant operation.

\section{CONCLUSIONS}

The understanding of potential thermal stress on power converter components during fault conditions is key to fully defining the protection requirements in future DC microgrids. The type of analysis described in this paper enables more effective system design by articulating the relationship between converter sizing and protection system speed. Ultimately this can then be translated into cost, as has been shown, which helps support design decision making.

The proposed low level component-based electro-thermal modelling approach used in this paper to characterize the thermal effects on power converters is universal in a sense that it can be applied for different converter topologies that operate at different ratings and conditions. Therefore, in a similar manner to cable designs or busbar configurations, a consistent procedure can be used to estimate the thermal effects of large high voltage power converters, where much greater cost can be reduced with appropriate trade-off between the selection of protection system design and size of a converter.

Results have further shown that semiconductors are the most vulnerable components against the short-term thermal stress, which is the consequence of their relatively short thermal time constant. Using nominal ratings, semiconductors may not withstand faults and their ratings may need to be improved. The additional cost of fault-tolerant semiconductors can be compensated with fast-acting dc protection, capable of clearing the faults in less than few milliseconds. Simulation results presented in this paper have also shown that implementation of fast-acting dc fault protection may be economically justified, especially for low ambient operating temperature conditions.

\section{REFERENCES}

[1] D. Salomonsson, L. Soder and A. Sannino, "Protection of Low-Voltage DC Microgrids," IEEE Trans. Power Delivery, vol. 24, pp.1045-1053, Jul. 2009.

[2] L. Mariam, M. Basu and M.F. Conlon. "A Review of Existing Microgrid Architectures," Journal of Engineering, vol. 2013, pp. 1-8, Mar. 2013.

[3] S. Backhaus, G. W. Swift, S. Chatzivasileiadis, W. Tschudi, S. Glover, M. Starke, J. Wang, M. Yue and D. Hammerstrom "DC Microgrids Scoping Study-Estimate of Technical and Economic Benefits" white paper from Los Alamos National Laboratory. [Online]. Available: energy.gov [accessed 5/01/16], March 2015.

[4] H. Lotfi and A. Khodaei, "AC Versus DC Microgrid Planning," IEEE Trans. Smart Grid, vol. 8, no. 1, pp. 296-304, Jan. 2017.

[5] S. Dhar, R. K. Patnaik and P. K. Dash, "Fault Detection and Location of Photovoltaic Based DC Microgrid Using Differential Protection Strategy," IEEE Trans. on Smart Grid, vol. PP, no.99, pp.1-1, Jan. 2017.

[6] J. Yang, "Protection issue discussion of DC network development: Circuit breaker or fault-tolerant converter," in Proc. DPSP 2012 Development in Power Systems Protection Int. Conf. pp. 1-6.

[7] S. Fletcher, P. Norman, K. Fong, S. Galloway and G. Burt, "High-Speed Differential Protection for Smart DC Distribution Systems," IEEE Trans. Smart Grid, vol.5, pp.2610-2617, Sept. 2014.

[8] A. Emhemed and G. Burt, "An Advanced Protection Scheme for Enabling an LVDC Last Mile Distribution Network," IEEE Trans. Smart Grids, vol.5, pp.2602-2609, Sept. 2014

[9] Short-circuit currents in d.c. auxiliary installations in power plants and substations, IEC Standard 61660, Jun. 1997.

[10] A. Emhemed and G. Burt, "The effectiveness of using IEC 61660 for characterising short-circuit currents of future low voltage DC distribution networks," in Proc. CIRED 2013 Electricity Distribution Int. Conf. and Exhibition, pp. 1-4.

[11] J. Yang, J. Fletcher, and J. O'Reilly, "Multiterminal dc wind farm collection grid internal fault analysis and protection design," IEEE Trans. Power Delivery, , vol. 25, no. 4, pp. 2308 -2318, Oct. 2010.

[12] S. Jin; Z. Huang; R. Diao; D. Wu; Y. Chen, "Comparative Implementation of High Performance Computing for Power System Dynamic Simulations," in IEEE Transactions on Smart Grid, vol. PP, no.99, pp.1-1, Jan. 2017.

[13] M. Hajian, D. Jovcic and B, Wu, "Evaluation of Semiconductor Based Methods for Fault Isolation on High Voltage DC Grids," IEEE Trans. Smart Grids, vol. 4, no. 2, pp. 1171-1179, Jun. 2013.

[14] M. Jamil, B. Hussain, M. Abu-Sara, R.J. Boltryk and S.M. Sharkh, "Microgrid power electronic converters: State of the art and future challenges," Universities Eng. Conf., pp. 1-5, Sept. 2009.

[15] R. Wu, F. Blaabjerg, H. Wang, M. Liserre and F. Iannuzzo, "Catastrophic failure and fault-tolerant design of IGBT power electronic converters - an overview," IEEE Industrial Electronics Society Conf., pp.507-513, Nov. 2013.

[16] 2005, APD Semiconductor - Application Note, "AN-1011: Defining Maximum Operating Junction Temperature (Tj)," Diodes Inc., United States. [Online]. Available: https://www.diodes.com

[17] W.K. Chen, VLSI Technology (Principles and Applications in Engineering), CRC Press, 2003, pp.8-18.

[18] Safety of transformers, reactors, power supply units and combinations thereof - Part 2-20: Particular requirements and tests for small reactors, IEC Standard 61558-2-20:2010, Nov. 2010. 
[19] A. Bossche and V. Valchew, Inductors and Transformers for Power Electronics, CRC Press Taylor \& Francis Group, 2005, pp. 276-280.

[20] P. Sun; C. Gong; X. Du; Q. Luo; H. Wang; L. Zhou, "Online Condition Monitoring for both IGBT Module and DC-Link Capacitor of Power Converter Based on Short-Circuit Current Simultaneously," IEEE Trans. on Industrial Electronics, vol. PP, no.99, pp.1-1, Jan. 2017.

[21] 2010, Bussmann ${ }^{\circledR}$ - Datasheet, "High Speed Fuses - Applications Guide," Copper Ltd., United Kingdom. [Online]. Available: https://www.bussmann.com

[22] User manual of PLECS blockset version 3.1, March 2011.

[23] V. Ivakhno, V. Zamaruiev and O. Ilina, "Estimation of Semiconductor Switching Losses under Hard Switching using Matlab/Simulink Subsystem," Journal of Elec., Control and Comm. Eng., vol. 2(1), pp. 20-26, May 2013.

[24] T. Setz, "Applying fast recovery diodes," Application Note 5SYA 20641, ABB Switzerland Ltd, 2013.

[25] A. Stupar, D. Bortis, U. Drofenik and J.W. Kolar, "Advanced setup for thermal cycling of power modules following definable junction temperature profiles," Int. Power Electronics Conf., pp. 962-969, June 2010.

[26] M. Chen, A. Hu and X. Yang, "Predicting IGBT Junction Temperature with Thermal Network Component Model," 2011 Asia-Pacific Power and Energy Engineering Conf., Wuhan, pp. 1-4, 2011.

[27] Heatsink for high power semiconductors - 177AB Series, ABL Components, UK. [Online]. Available: http://uk.rs-online.com/

[28] IGBT Modules $600 \mathrm{~V} 150$ A Dual - BSM150GB60DLC, Infineon Technologies, Germany. [Online]. Available: http://eu.mouser.com/

[29] 2012, ATI Properties, "Grain-Oriented Electrical Steel - Technical Data sheet," USA. [Online]. Available: https://www.atimetals.com/

[30] 2011, MTE Corp., "AC Line / Load Reactors - Reactor Selection \& Pricing," USA. [Online]. Available: http://www.mtecorp.com/

[31] 2015, DC Film Capacitor - B25620B447K882-ND, EPCOS (TDK), USA. [Online]. Available: http://www.digikey.com/

[32] R. Schnell, "Paralleling of IGBT modules," Application Note 5SYA 2098-00, ABB Switzerland Ltd, 2013.

[33] RL Line / Load Reactors - Selection Table, Technical Details \& Product Application Guide, MTE Corp., 2008, USA. [Online].

[34] R. Burkart and J.W. Kolar, "Component Cost Models for MultiObjective Optimizations of Switched-Mode Power Converters," IEEE Energy Conversion Congress and Exposition (ECCE), pp. 2139-2146, Sep. 2013.

\section{BIOGRAPHIES}

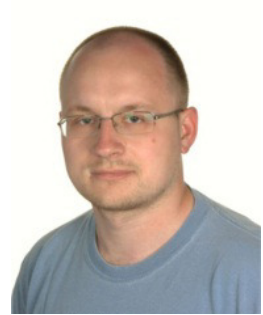

Michal Sztykiel received his MEng degree in electrical engineering from Gdansk University of Technology, Gdansk, Poland in 2009 and his PhD degree from Aalborg University, Aalborg, Denmark in 2014. From 2014 he is a research associate at University of Strathclyde, Glasgow UK. His main research interests include design, modelling and protection of wind power plants, marine and aerospace electrical systems.

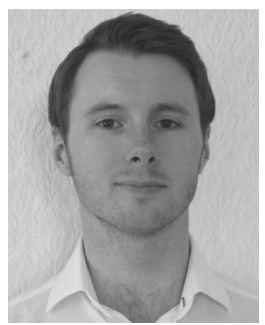

Steven Fletcher (M'13) received his BEng degree in electrical and electronic engineering from the University of Strathclyde, Glasgow, U.K in 2007 and his $\mathrm{PhD}$ degree from University of Strathclyde in 2013, following research into dc network protection. $\mathrm{He}$ is currently a research associate within the Institute for Energy and Environment at Strathclyde. His research interests include the design, modelling and protection of microgrid, marine and aerospace power systems.

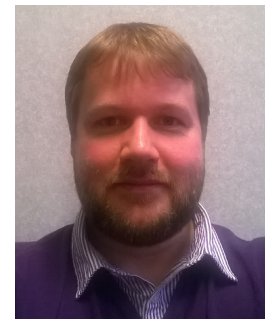

Patrick Norman is a lecturer within the Inst itute for Energy and Environment at the University of Strathclyde. He received his BEng (Hons) degree in electrical and mechanical engineering and $\mathrm{PhD}$ in electrical engineering from the University of Strathclyde. His research interests lie in the modelling and simulation, design, control, protection of aircraft secondary power offtake and distribution systems, microgrid and shipboard power systems.

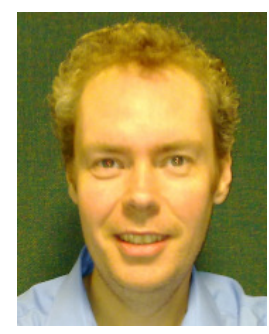

Stuart Galloway received his Bachelors degree in Mathematical Sciences form the University of Paisley in 1992. He obtained his M.Sc. degree in Non-linear Modelling (1993) and $\mathrm{PhD}$ in Numerical Analysis (1998) from the University of Edinburgh, UK. Since 1998 he has been researching optimisation problems in power systems, electricity markets and novel architectures relating to aero and marine systems. $\mathrm{He}$ is currently a Reader in the Institute for Energy and Environment at the University of Strathclyde.

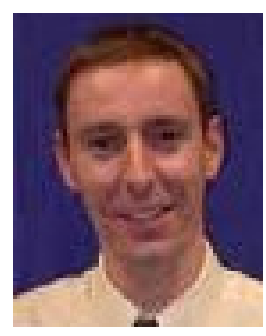

Graeme M. Burt (M'95) received the B.Eng. degree in electrical and electronic engineering from the University of Strathclyde, Glasgow, UK, in 1988, and the $\mathrm{Ph} . \mathrm{D}$. degree from the University of Strathclyde in 1992, following research into fault diagnostic techniques for power networks. He is currently a Director of the Institute for Energy and Environment at the University of Strathclyde, where he also directs the University Technology Centre in Electrical Power Systems sponsored by Rolls-Royce. He is a professor of electrical power engineering, and has research interests in the areas of: integration of distributed generation; power system modelling, real-time simulation, protection and control; microgrids and more-electric systems. 